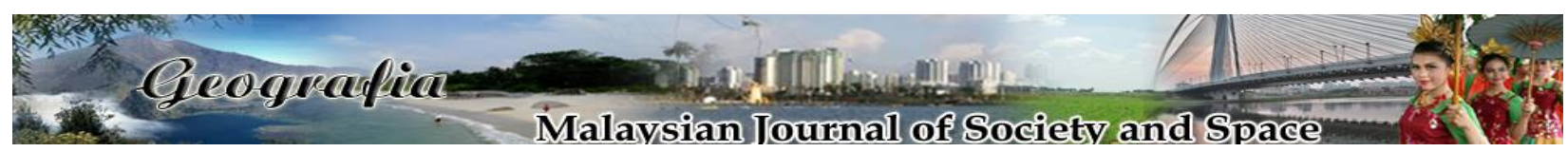

\title{
Evaluation of climate variability impact on sources of water supply
}

\author{
Olanrewaju, R. M., Adedoyin, F., Akpan, G. P. \\ Department of Geography and Environmental Management, University of Ilorin, Nigeria \\ Correspondence: Olanrewaju, R. M (email: rodamoji@gmail.com)
}

Received: 06 May 2019; Accepted: 28 June 2019; Published: 22 August 2019

\begin{abstract}
Climate is a key factor in water availability and accessibility on both the earth surface and below the earth surface. The study evaluated climate variability impact on sources of water supply in Offa, Kwara State, Nigeria. The study utilized both primary and secondary source of data. Household proximity to water sources was computed using the percentages of household that falls within the basic indicator for measuring water access by World Health Organization. Correlation and multiple regression analyses were used to determine the relationship between the climatic variables and water supply; and groundwater level in the study area. Pearson Product Moment Correlation was employed to establish the association between climate and water supply; and groundwater level. Multiple regression analysis was used to examine the relationship between water supply and the selected climatic variables. Trend analysis was used to determine the trend of the selected climatic variables in the study area. The result revealed that rainfall amount, minimum and maximum temperature, and evaporation exhibit an upward trend which are not statistically significant. The fluctuating trend in these climatic variables, though not statistically significant are probably related to the already established changes in climatic parameters in Nigeria. The result also showed that the spatial distributions of public boreholes in the study area are heterogeneous in nature. The study recommended that the clustering of water sources, especially the shallow wells should be discouraged to avoid over abstraction of groundwater in the study area.
\end{abstract}

Keywords: climate, climate variability, sources of water, water accessibility, water availability, water supply,

\section{Introduction}

Human welfare and economic development generally depend on the use of water. Water is a precious natural resource, vital for life. According to the Asian-Pacific Economic Cooperation (APEC Water, 2017), water makes up more than two thirds of the weight of the human body, and without it, we would die in a few days. The World Health Organization (WHO)/United Nations 
Children's Fund Joint Monitoring Program (UNCFJMP), in its 2012 progress report on drinking water and sanitation, has ranked Nigeria third behind China and India on the list of countries with the largest population without access to improved drinking water. Globally, the report noted that in 2010, 89 per cent of the world's population, or 6.1 billion people, used improved drinking water sources, exceeding the Millennium Development Goal of 88 per cent; while 92 per cent are expected to have access in 2015.

The inadequacy of safe water to the entire population is manifested in the prevalence of water related diseases such as guinea worm, cholera, diarrhea and dysentery among others. Many water resources in developing countries such as Nigeria are unhealthy because they contain harmful physical and biological agents. To maintain a good health however, water should be safe to drink and meet the local standards and international standard to taste, odour and appearance (Chessbrough, 2000).

Climate variability is the variation in the mean State and other statistics of climate on all temporal and spatial scales beyond that of individual weather events (Climate Change Glossary, 2012). Climate is a key factor in water availability and accessibility on both the earth surface and below the earth surface. This is because, the only natural input to the main sources of water (surface and ground water) is rainfall which is relied on for both surface and groundwater (Taylor \& Callist, 2011). Long term fluctuations in rainfall distribution pattern around the world have been linked to the effect of climate change (Scott, 2004; Taylor \& Callist, 2011). According to Olanrewaju and Akpan (2016), one of the factors exacerbating the problem of water availability and accessibility in Nigeria is climate variability.

Nigeria is one of the eight countries in the world having between only 50 and 75 per cent of their urban population accessing improved drinking water while access to potable water supply in most places in Nigeria is bedeviled by lack of access to clean potable water supply, skewed spatial distribution and political influences as well as climate influence which warrants uneven distribution of public water supply. This has led to residents sourcing for alternative sources of water by digging wells and in some extreme cases making do with water from unhygienic sources which in the long run has health implications and contravenes the WHO standard of water supply.

Solar radiation and temperature are factors that play a big role on how moisture is lost from the earth surface. Temperatures are likely to increase across the countries such as Nigeria exacerbating other climatic impact (John, 2009). This suggests that the intensity and frequency of climate variability and change in the country may be worse in the near future and pose serious implications on sources of water supply.

Offa like every other town in Nigeria is increasing in population which has led to increase demand for quality water supply such as treated pipe borne water apart from the traditional well which might have dried up especially during the dry season. Studies have shown that the public water sources and supply in Offa cannot meet the increasing population of the town (Adedayo \& Ifabiyi, 1999). It is on this premise that the study aimed at evaluating climate variability impact on sources of water supply in Offa. The study specifically examined the spatial distribution of various water sources and households' proximity to the water supply sources in the study area and evaluated the relationships between climate variables and various sources of water supply with a view to determining if sources of water supply are affected by climate variability. 


\section{Literature review}

\section{Impact of climate variability on water resource}

The impact of climate change and variability on water resources vary widely by regions and there are places having greater variability than others, but it is certainly no area that has not experience the impact of climate variability.

Climate variability will affect the water resource base for many water utilities. Higher temperatures and reduced precipitation levels will cause shortages in available supply due to slower replenishment rates of underground water resources and/or reduced availability of surface water. Rising seawater levels and inland flooding will cause land inundation and blockages in natural drainage structures. According to Environmental Resource Management (ERM, 2009), these effects will be even more difficult to manage for those water utilities that are unprepared and/or financially weak.

Climate is the key factor in water supply planning and climate change is expected to affect water supplies in various ways. The fundamental components of weather are temperature, precipitation, wind, solar radiation, humidity, air pressure and cloud cover. Temperature, precipitation and wind are the primary factors affecting surface water quality. These components are expected to vary substantially with climate change (Wright et al., 2013).

The effect on water quality often results from a combination or a series of weather events that may occur rapidly or over a period of months to years. For example, multiple components may occur simultaneously: droughts coincide with high temperatures; storms, hurricanes, and tornadoes bring heavy rains and strong winds. Alternately, extended drought may be followed by heavy rains that negatively affect turbidity, contaminant concentrations, and organic matter in raw water supplies.

Changes in surface runoffs and groundwater flows in shallow aquifers is part of the hydrological processes that can be linked to climate variability, with implications for permanent and seasonal water bodies such as lakes and reservoirs (Wright et al., 2013). There is evidence of a broadly coherent pattern of change in annual runoff at the global scale, with some regions, particularly at high altitudes, experiencing an increase while others experience a decrease, for example in parts of Africa (Mulcheiber \& Sparks, 2005).

While lake levels in other parts of the world have risen (e.g. in Mongolia and China) in response to increased snow- and ice melt, lake levels in Africa particularly Lake Chad has declined due to the combined effects of drought, warming and human activities (IPCC, 2001).

Rainfall is a renewable resource, highly variable in space and time, and subject to depletion or enhancement due to both natural and anthropogenic causes (Abaje, 2010). In Nigeria, changing rainfall patterns have been observed by researchers such as Nnaji (2001) and Ulor (2006) among others. Nnaji (2001) observed unusual change in the occurrences of wet and dry season regimes in sub-Saharan Africa, while annual decadal and inter decadal variations in rainfall have been reported by Anyadike (1993) and Ulor (2006). Odjugo (2005, 2009) observed decline in rainfall amount in Nigeria. The decreasing rainfall, increasing temperature and evapotranspiration have resulted in either reduction of water levels or total dry up of some rivers and other water bodies. 


\section{Impacts of climate variability on surface and groundwater systems}

The potential effects of climate variability and change on water resources are well recognized globally and have been identified as a major issue facing the availability of groundwater resources in the world (Alley et al., 1999). In recent decades, many scientific studies have improved understanding of the effects of climate change on water resources; however, research has focused primarily on surface water because of the visibility, accessibility, and more obvious recognition of climate effects on surface water than on groundwater. Although recent research has begun to focus more on understanding the effects of climate variability and change on groundwater quantity and quality, the effects remain poorly understood (Green et al., 2007). Climate variability and change can affect the quantity and quality of various components in the global hydrologic cycle.

In arid and semi-arid regions, with poor access to surface water, groundwater plays a major role in meeting domestic as well as irrigation demands. It is also essential for providing informal and private access to populations not served by municipal water utilities. It is estimated by the United Nations that 2 billion people depend on groundwater. Since the 1970s groundwater use has helped in achieving food sufficiency and drinking water security in many Asian and Middle Eastern as well as African countries. Comprehensive Assessment of Water Management in Agriculture (CA, 2007) noted that lack of proper planning, ineffective legislation and poor governance have jeopardized many groundwater aquifers. Climate variability and change are expected to reduce surface water supplies and result in a greater reliance on groundwater particularly in semi-arid and arid regions. At the same time, replenishment of groundwater may be hindered due to hydro-climatic changes and demographic, socioeconomic and institutional factors that will bring in more challenges for sustainable groundwater management. Reduced precipitation and continued abstraction will affect replenishment rates of groundwater resulting in declining water tables if the net recharge rate is exceeded. Often over-exploitation of groundwater magnifies inherent salts such as total dissolved solids (TDS), fluorides and chlorides. The problem of groundwater over-exploitation is self-limiting owing to higher pumping cost, deteriorating quality and treatment cost, and subsequent reduction of the resource.

The quality of surface water bodies will be affected negatively under climate change and climate variability particularly when high intensity rainfalls generate significant surface runoff that may carry significant sediment loads containing pesticides, fertilizers and wastes. The high sediment loads may increase siltation in streams, lakes and impoundments.

\section{Methods and study area}

Offa is located in South-East of Ilorin, the capital of Kwara State of Nigeria. The town is situated between Latitude $8^{\circ} 6^{\prime}$ and $8^{\circ} 22^{\prime}$ North of the Equator and Longitude $4^{\circ} 41^{\prime}$ and $4^{\circ} 74^{\prime}$ East of the Greenwich Meridian (Figure 1). It is situated on $344 \mathrm{~km}$ on the South/North (SN) rail line from Lagos (Abdulsalam, 2009). It has a total population of 89,674 (NPC, 2006) and 2018 projected population is 126,372 at a growth rate of $2.9 \%$.

Based on Koppen-Geiger climatic classification, Offa lies within the Equatorial Savannah. The climate of the Local Government Area is influenced by two major winds: the Tropical Maritime Air Mass which is predominant between March and October, and the Tropical Continental Air Mass which also predominant between November and February. This 
gives rise to two major seasons: the wet and dry seasons. The wet season starts in April and ends in October, while dry season spans between November and March. The months of December through January are usually characterized by a dry-cold-dust laden harmattan wind from the Sahara Desert.

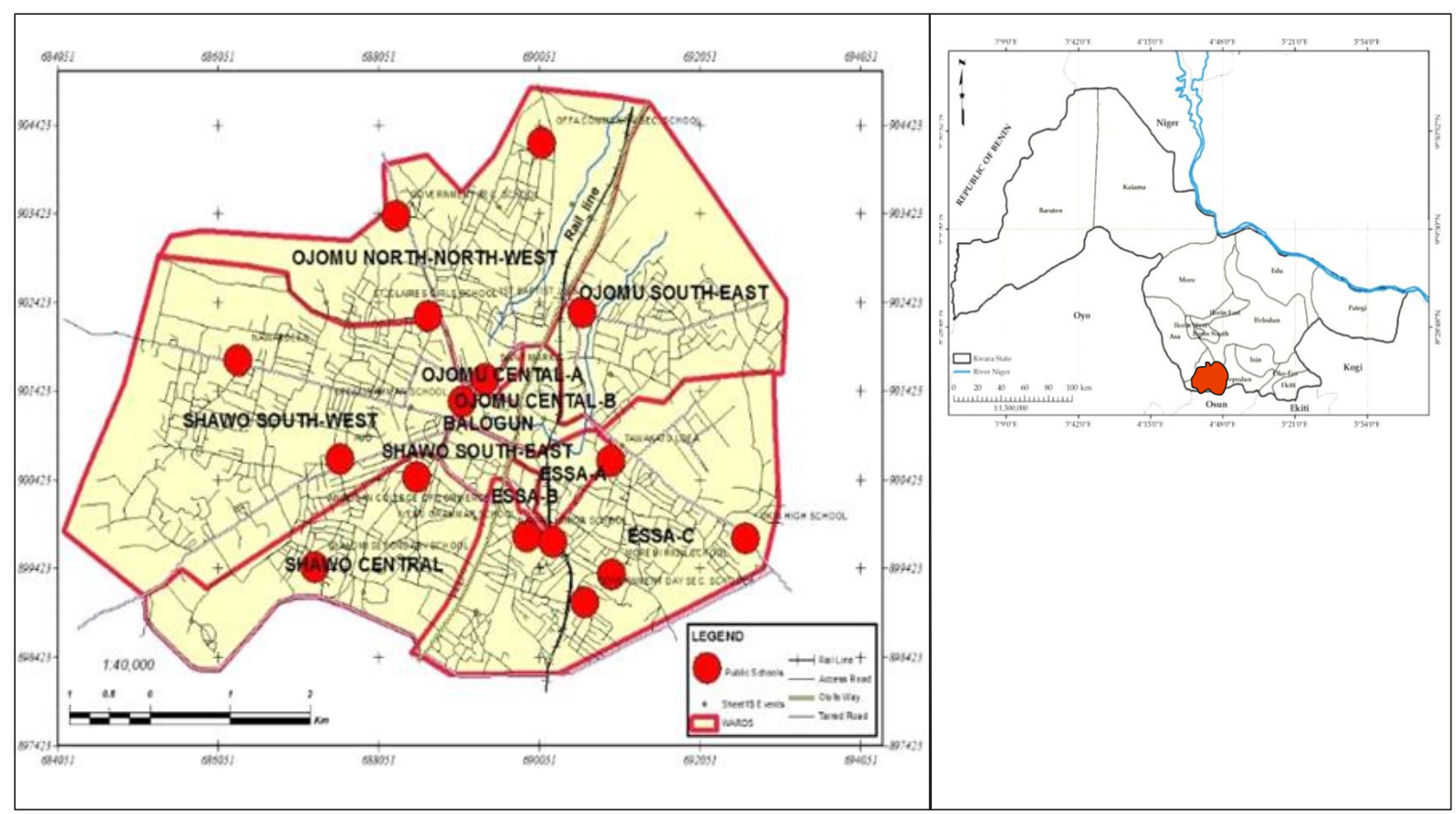

Source: Offa Local Government Secretariat, 2017

Figure 1. Study area with Political Wards (Political map of Kwara State inset)

The average annual temperature in Offa is $25.7{ }^{\circ} \mathrm{C}$ while the average rainfall is $1250 \mathrm{~mm}$. Rainfall is very low in January with an average of $10 \mathrm{~mm}$ and highest in September with an average of $210 \mathrm{~mm}$. March is the hottest month of the year with a temperature of $36{ }^{\circ} \mathrm{C}$ while the month of August has the minimum average temperature of $23.4{ }^{\circ} \mathrm{C}$. Hand dug shallow well and borehole are the common sources of water in Offa.

The study utilized both primary and secondary sources of data. The coordinates of water sources were obtained on the field by the researchers using handheld Global Positioning System (GPS). Groundwater level was recorded with the use of improvised well estimator while data on household proximity to water sources were collected through the use of a structured questionnaire. Similarly, climatic data was sourced from Nigeria Meteorological Agency (NIMET) Ilorin the nearest reliable weather station, while data on quantity of water supply (liters) for the period of study was obtained from Kwara State Water Cooperation for Offa LGA. The household proximity to water sources was computed using the percentages of household that falls within the basic indicator for measuring water access by World Health Organization (2005), which revolves around distance and time. Correlation and multiple regression analyses were used to determine the relationship between the climatic variables and water supply; and groundwater level in the study area. Pearson Product Moment Correlation was employed to establish the association between climate and water supply; and groundwater level. Multiple regression analysis was used to examine the relationship between water supply and the selected climatic variables. Trend analysis was used to determine the trend of the selected climatic variables in the 
study area.

\section{Results and discussion}

Trend analysis of the climatic variables in study area

The result of the trend analysis using regression method for all the climatic variables is presented in Table 1. The nature of trend and the level of significance are presented and highlighted, while trend line graphs are presented to reveal the visual fluctuation in the climatic parameters used during the period of study.

\section{Trend in rainfall amount 1988-2017}

The result of the linear regression analysis indicates that there is no statistically significant relationship between rainfall amount and year at 95\% confidence level (Table 1). The R-squared statistic reveals that the model, as fitted, explains $0.0001 \%$ variability in rainfall amount in the study area. The correlation coefficient of 0.007 reveals a positive relationship between rainfall amount and time (year). The result revealed that rainfall amount exhibits an upward trend in the study area which is not statistically significant and cannot be attributed to any cause. Therefore, the increasing trend in rainfall amount into the future based on the record used in this study cannot be ascertained. This is in line with the observation made by Wright et al. (2013).

Table 1. Climatic trend in the study area, 1988-2017

\begin{tabular}{lccccc}
\hline Weather Variables & P-value & $\begin{array}{c}\text { Regression } \\
\text { equation }\end{array}$ & $\begin{array}{c}\text { Sample } \\
\text { correlation }\end{array}$ & $\begin{array}{c}\text { Trend } \\
\text { Significance }\end{array}$ & $\mathbf{R}^{2}$ \\
\hline Rainfall amount & .970 & $\mathrm{Y}=1145.1+0.189 \mathrm{X}$ & .007 & Not Significant & $0.0001 \%$ \\
Minimum temperature & .489 & $\mathrm{Y}=21.465+0.0058 \mathrm{X}$ & .017 & Not Significant & $1.7 \%$ \\
Maximum temperature & .271 & $\mathrm{Y}=32.116+0.0082 \mathrm{X}$ & .043 & Not Significant & $4.31 \%$ \\
Evaporation & .885 & $\mathrm{Y}=5.474+0.0012 \mathrm{X}$ & .001 & Not Significant & $0.01 \%$ \\
Relative humidity & .001 & $\mathrm{Y}=71.814+0.1604 \mathrm{X}$ & .324 & Significant & $32.4 \%$ \\
\hline
\end{tabular}

Source: Authors' computation, 2018

Figure 2 was obtained from the plot of rainfall amount against time and it shows a positive trend line. Although there was yearly fluctuation in rainfall amount, which was notable from the year 1990 to 2010, the trend line equation, revealed that the rainfall amount increased at a low rate of $0.189 \mathrm{~mm} /$ year between 1988 and 2017 . 


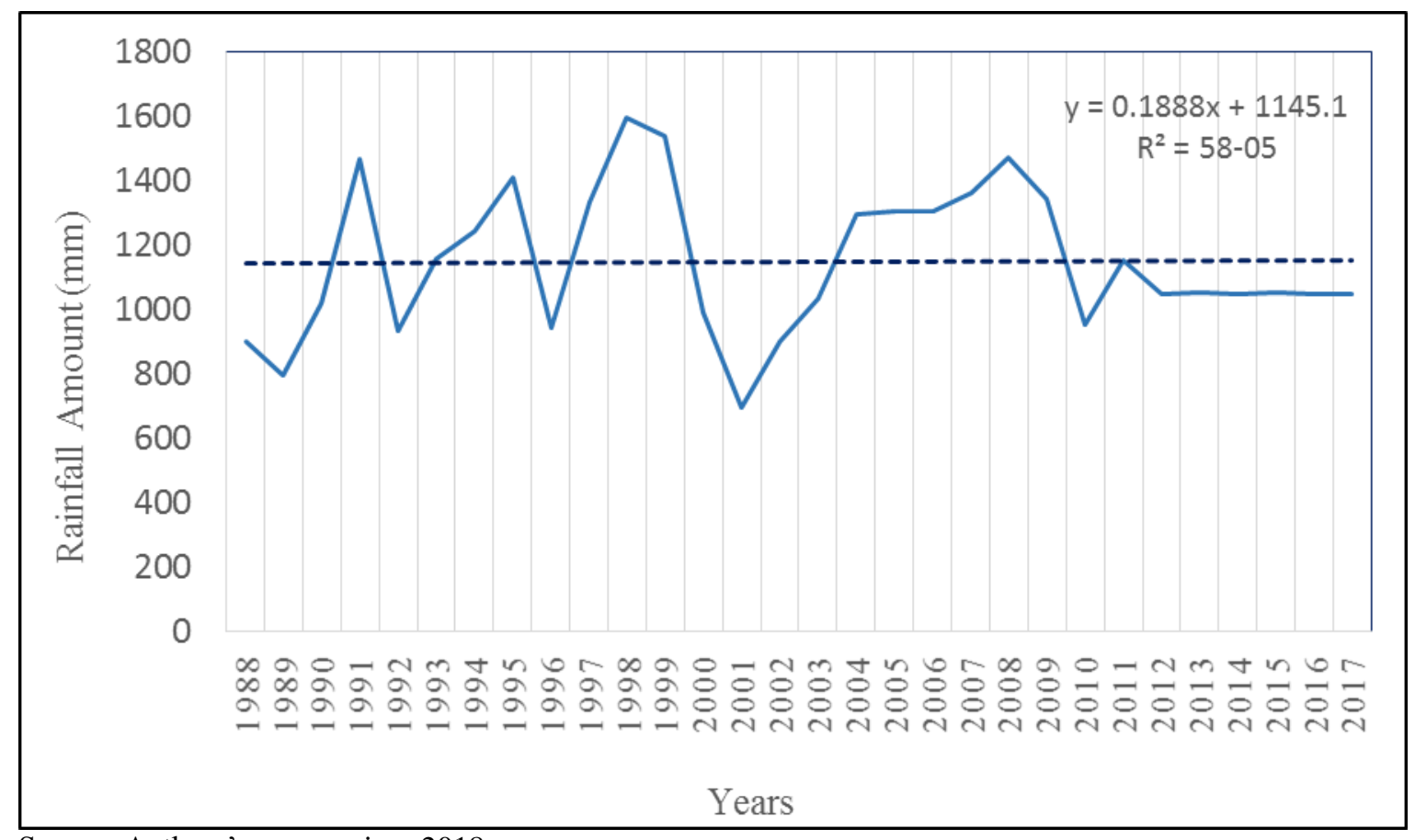

Source: Authors' computation, 2018

Figure 2. Trend in rainfall amount with time in the study area, 1988-2017

\section{Trend in minimum temperature between 1988 and 2017}

Table 1 and Figure 3 show that minimum temperature exhibits an upward trend during the period under consideration. In other words, the results of regression trend analysis reveal that there is no statistically significant relationship between minimum temperature and year at $95 \%$ confidence level. The result indicated that although minimum temperature is increasing, the possibility of the continuity of this trend into the future cannot be ascertained. The correlation coefficient of 0.017 reflects a positive relationship between minimum temperature and time (year) confirming the above findings. The R-squared statistic reveals that the model, as fitted, explains $17 \%$ variability in minimum temperature in the study area. Figure 3 shows a positive trend line, which implies minimum temperature increased at a rate of $0.0058{ }^{\circ} \mathrm{C} /$ year between 1988 and 2017. 


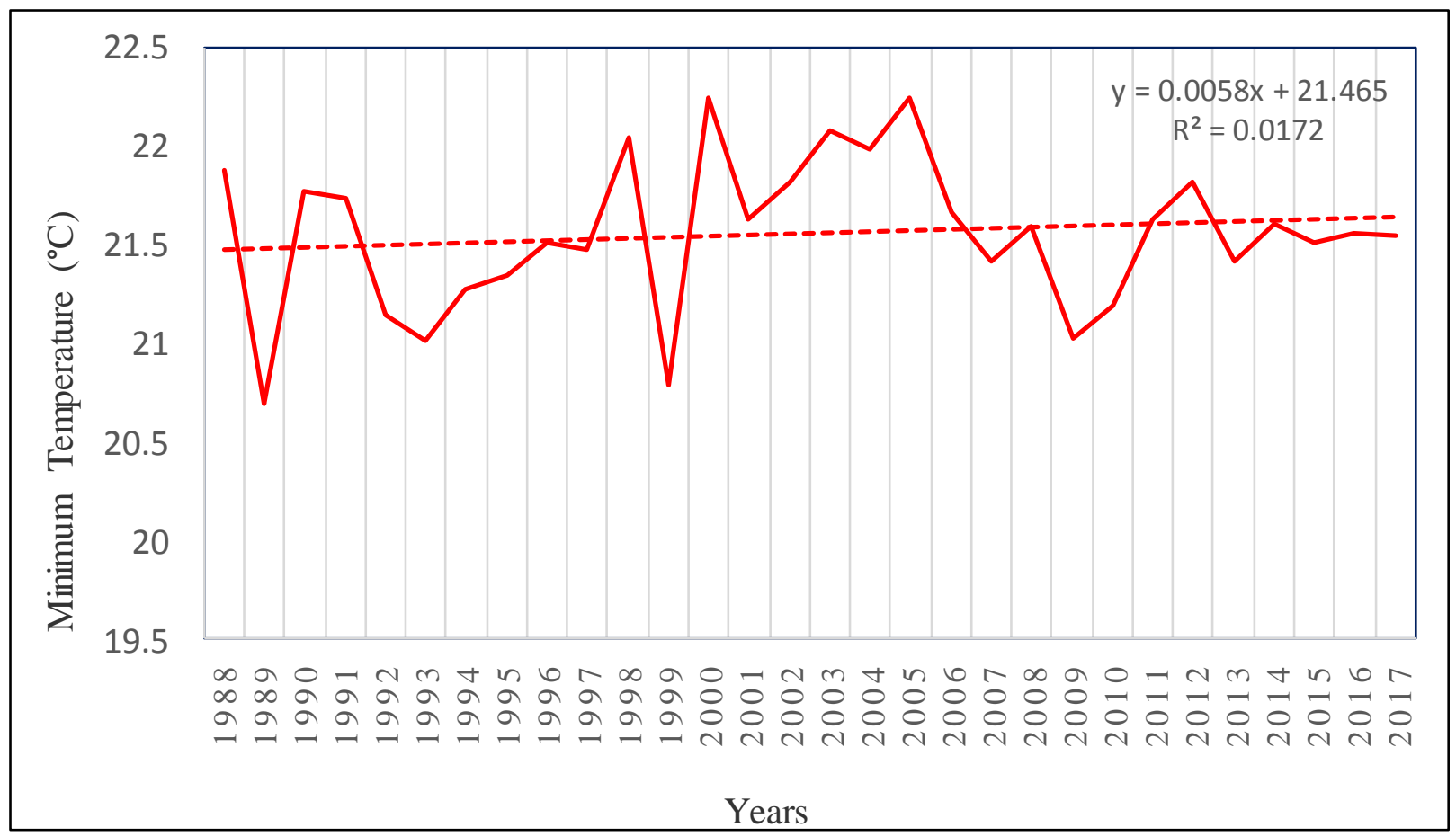

Source: Authors' computation, 2018

Figure 3. Trend in minimum temperature with time in the study area, 1988-2017

Trend in maximum temperature 1988-2017

Table 1 and Figure 4 reflect the trend in maximum temperature in the study area between 1988 and 2017. It was observed that maximum temperature is on the increase. The trend line equation indicates that maximum temperature increased at the rate of $0.0082{ }^{\circ} \mathrm{C} / \mathrm{year}$ between 1988 and 2017 during the period of study. However, yearly fluctuation occurs throughout the period of investigation. The correlation coefficient of 0.043 reflects a positive relationship between maximum temperature and time (year) that suggests an upward trend. The R-squared statistic reveals that the model, as fitted, explains $4.31 \%$ variability in maximum temperature in the study area. This result is similar to the report of Naga et al. (2018) and Makanjuala et al. (2010). 


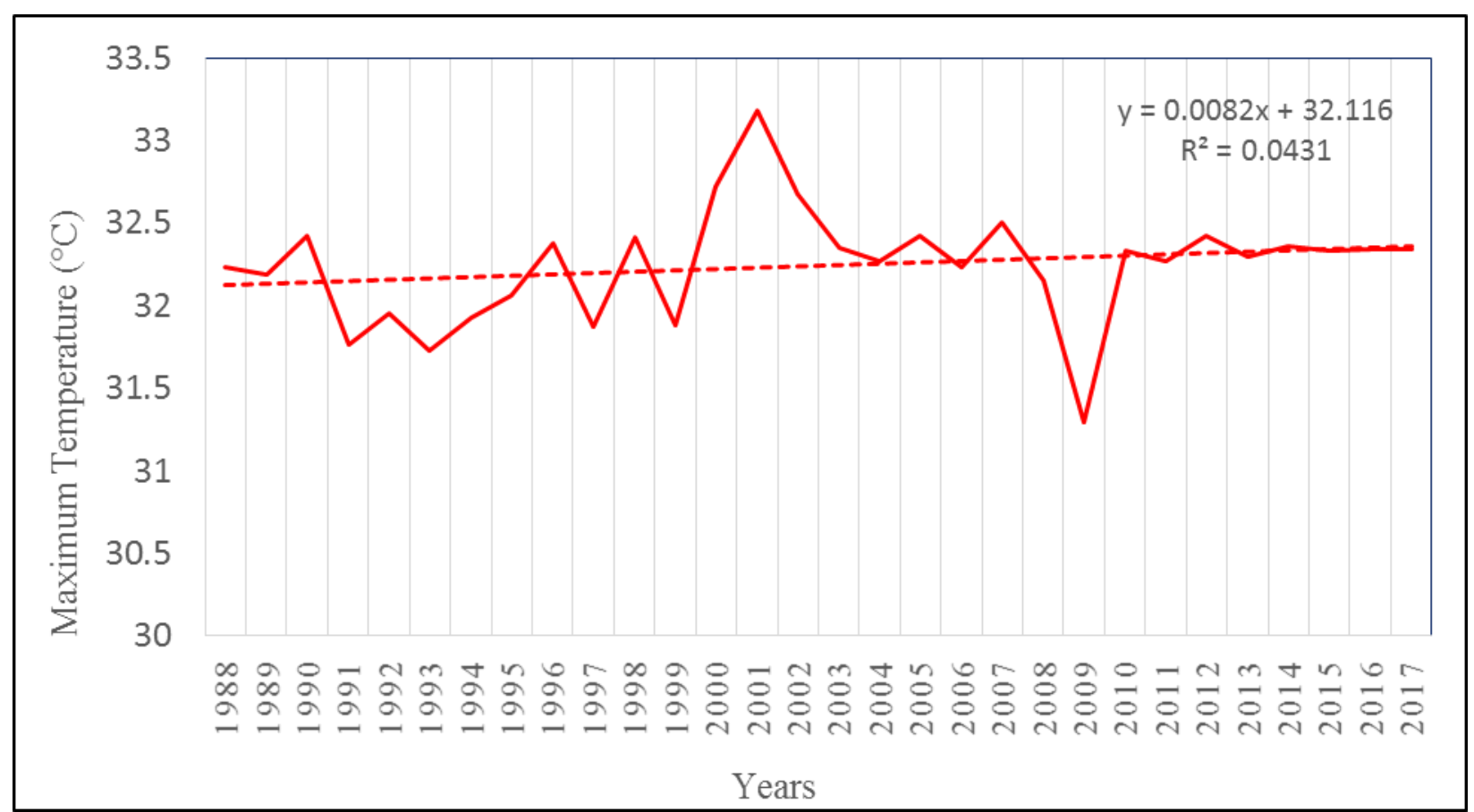

Source: Authors' computation, 2018

Figure 4. Trend in maximum temperature with time in the study area, 1988-2017

\section{Trend in evaporation 1988-2017}

The result of the regression trend analysis indicates no statistically significant relationship between evaporation and year at $95 \%$ confidence level (Table 1). The correlation coefficient of 0.001 reveals a weak positive relationship between evaporation and time (year). The result indicates that the upward trend observed might not continue into the future. The R-squared statistic reveals that the model, as fitted, explains $0.01 \%$ variability in evaporation in the study area. Figure 5 shows the upward trend in evaporation over the 30 years of study. From the trend line equation, it can be deduced that evaporation is increasing at a low rate of $0.0012 \mathrm{~mm} / \mathrm{year}$ during this period. 


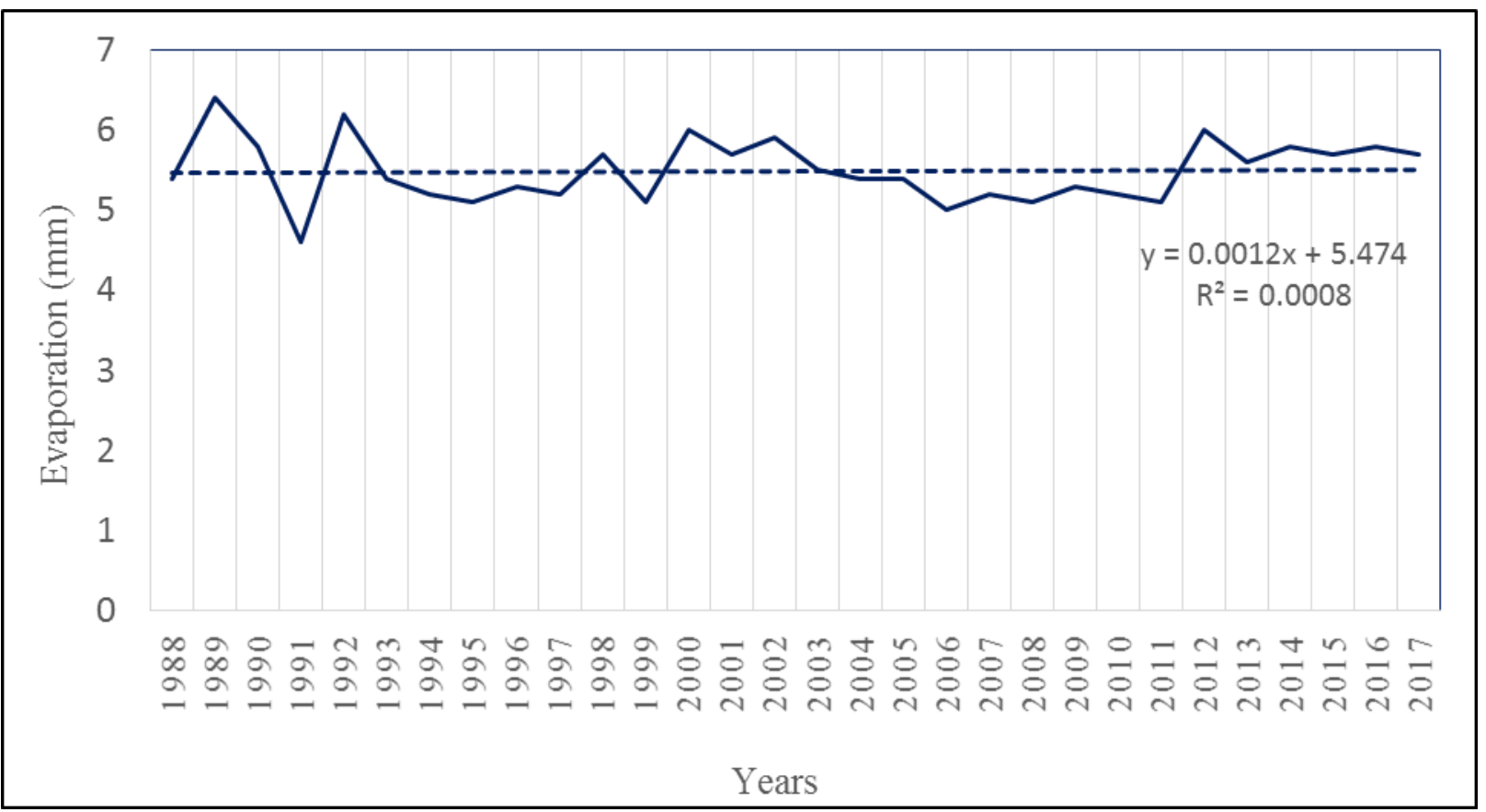

Source: Authors' computation, 2018

Figure 5. Trend in evaporation with time in the study area, 1988-2017

Trend in relative humidity (1988-2017)

An upward trend in relative humidity was obtained from the regression trend analysis which is statistically significant (Table 1). Hence, this observed trend can be said to have a particular cause and the continuation of the upward trend into the future is certain. In other words, the result shows that there is a statistically significant relationship between relative humidity and year at $95 \%$ confidence level. Figure 6 shows an increasing trend at the rate of $0.16 \%$ every year during the period with yearly fluctuations. It is not unlikely that the present situation among others was responsible for the slight increase in rainfall trend observed during this period. 


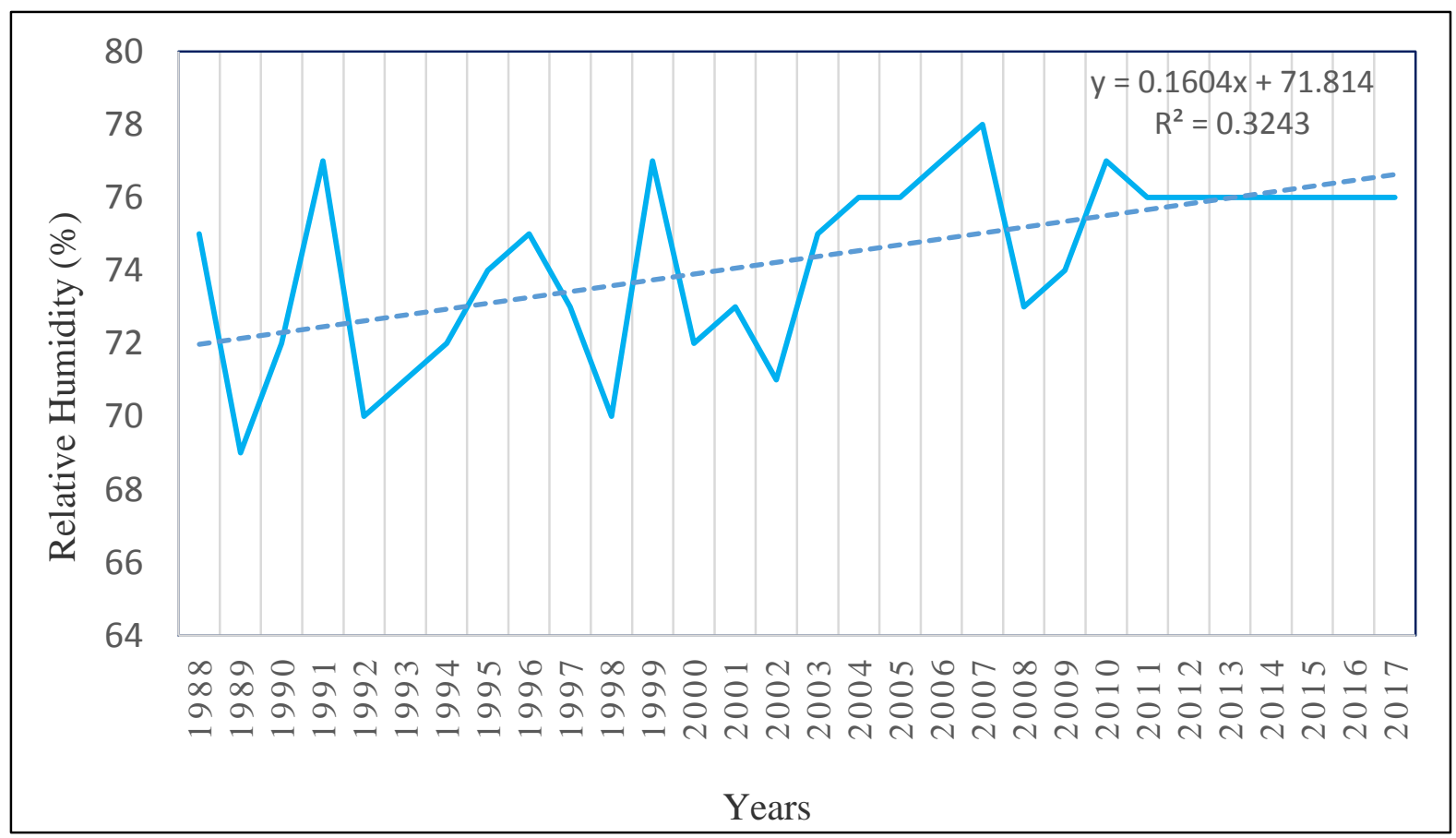

Source: Authors' computation, 2018

Figure 6. Trend in relative humidity with time in the study area, 1988-2017

\section{Various sources of water supply and household proximity}

Table 2 shows the spatial distribution of various public water sources in the study area. Three water sources were identified in the study area; which are shallow well, borehole and river. The total number of well, borehole and river identified in the study were 86, 42 and 2, respectively. Ojomu central "A" political ward, Ojomu central "B" political ward, Shawo south-east political ward and Balogun political ward have the highest (10) number of shallow wells, while Ojomu north-west and Igbodun political wards have the lowest (4) number of shallow wells (Table 2). Balogun political ward has the highest number (8) of boreholes, while Shawo south west political ward has the lowest (3). Ojomu central A and B, as well as Shawo south east political ward have no borehole, they are however, the wards with the highest number of shallow wells (10) in the study area.

The average number of shallow well per wards is 7.2, with a coefficient of variation of $34.72 \%$, which indicated that number of shallow well per ward is highly varied. On the other hand, the average number of borehole per ward is 4.3 , with a coefficient of variation of $39.3 \%$, which indicated that borehole distribution in the study area is heterogeneous. It is important to note that most of these public boreholes are drilled in the respective wards as a kind of political gain to the people. Therefore, the reasons for the high variability in the number of borehole per wards may not be unconnected with the cost of drilling borehole and the political leaders in each of the wards. 
Table 2. Spatial distribution of various public water sources in the study area

\begin{tabular}{lccc}
\hline Wards & \multicolumn{3}{c}{ Type of water sources } \\
\cline { 2 - 4 } & Shallow well & Borehole & River \\
\hline Ojomu South-east & 6 & 4 & 2 \\
Ojomu North-west & 4 & 6 & - \\
Ojomu Central "A" Political Ward & 10 & - & - \\
Ojomu Central "B" Political Ward & 10 & - & - \\
Igbodun Political Ward & 4 & 6 & - \\
Shawo South-west Political Ward & 7 & 3 & - \\
Shawo Central Political Ward & 5 & 5 & - \\
Shawo South-east Political Ward & 10 & - & - \\
Essa "A" Political Ward & 6 & 4 & - \\
Essa "B" Political Ward & 9 & 1 & - \\
Essa "C" Political Ward & 5 & 5 & - \\
Balogun Political Ward & 10 & - & - \\
Total & 86 & 34 & 2 \\
Average & 7.2 & 4.3 & 2 \\
Standard Deviation & 2.5 & 1.67 & - \\
CV (\%) & 34.72 & 39.3 & - \\
\hline
\end{tabular}

Source: Authors' computation, 2018

The spatial distribution of the identified water sources in the study area is presented in Figure 7. The pattern of water sources in the study area revealed that shallow wells are concentrated in the central part of the study area and towards the north. This might be a resultant effect of the geological structure of the rock, which makes the water table close to the surface. Again it is important to note that this central place of the study area constitutes where majority of the population are concentrated. The result of the nearest neighbor analysis shows a value of 0.89 , which indicated that the water sources in the study area are clustered (Table 3). Given the $\mathrm{z}$-score of -2.201 , there is a less than $5 \%$ likelihood that the clustered pattern observed could be the result of random chance. 


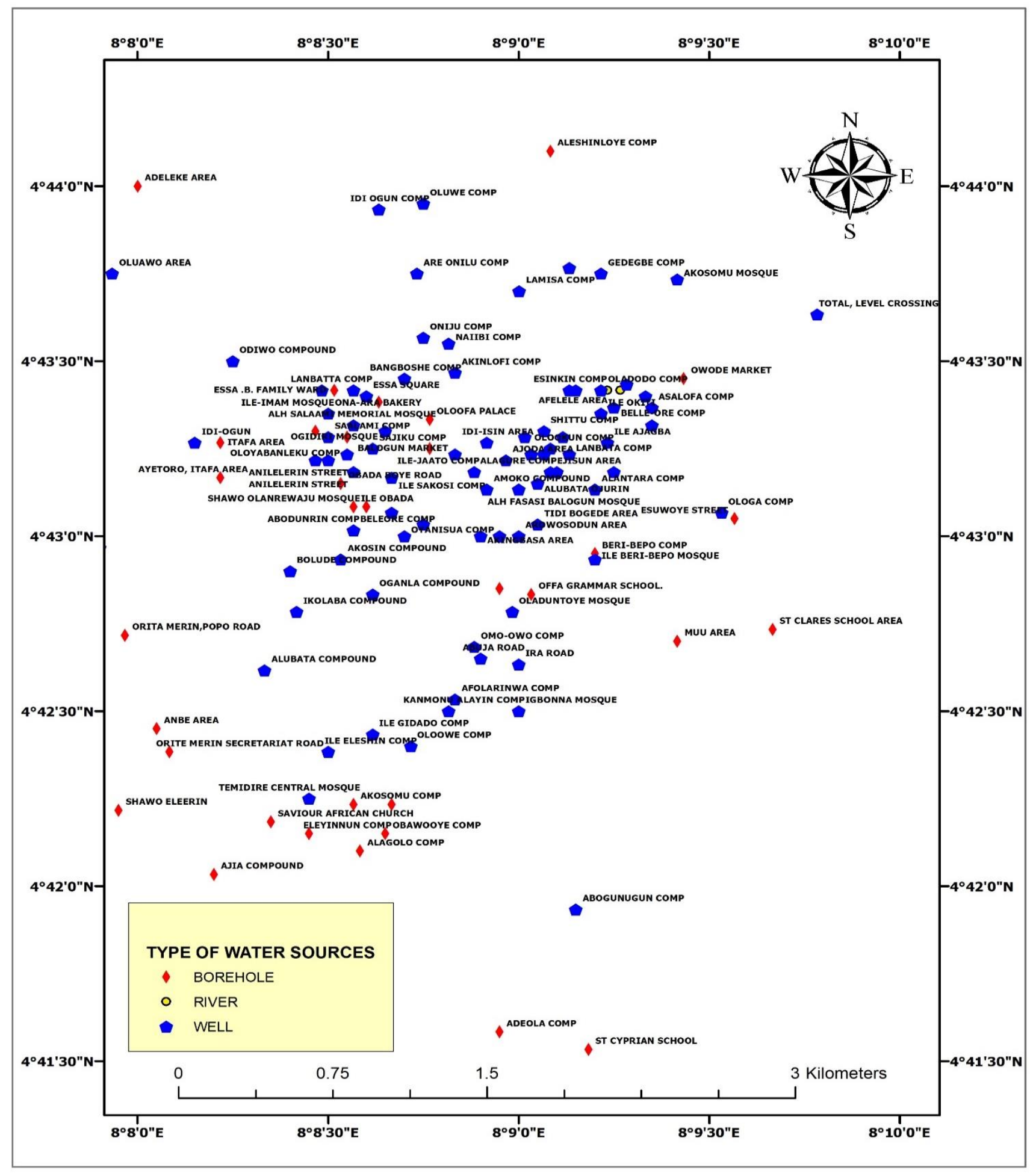

Source: Authors' fieldwork, 2018

Figure 7. Spatial distribution of water sources in the study area 
Table 3. Average nearest neighbor of the water sources in the study area

\begin{tabular}{lcccc}
\hline Observed mean distance & $\begin{array}{c}\text { Expected mean } \\
\text { distance }\end{array}$ & $\begin{array}{c}\text { Nearest neighbor } \\
\text { ratio }\end{array}$ & z-score & p-value \\
\hline 163.2139 Meters & 182.3682 Meters & 0.894969 & -2.201102 & 0.027729 \\
\hline
\end{tabular}

Source: Author's computation, 2018

Figure 8 shows the graphical representation of water sources distribution pattern in the study area. The study revealed that well and borehole are the major sources of water in the study area. The reason for the clustered pattern in water distribution in the study area may be linked to the geological location of the study area on a basement complex aquifer, which is a shallow aquifer that encourages proliferation of hand dug wells because of the low cost of digging. The implication of the clustered pattern observed, is that there may be over abstraction of groundwater in the study area.

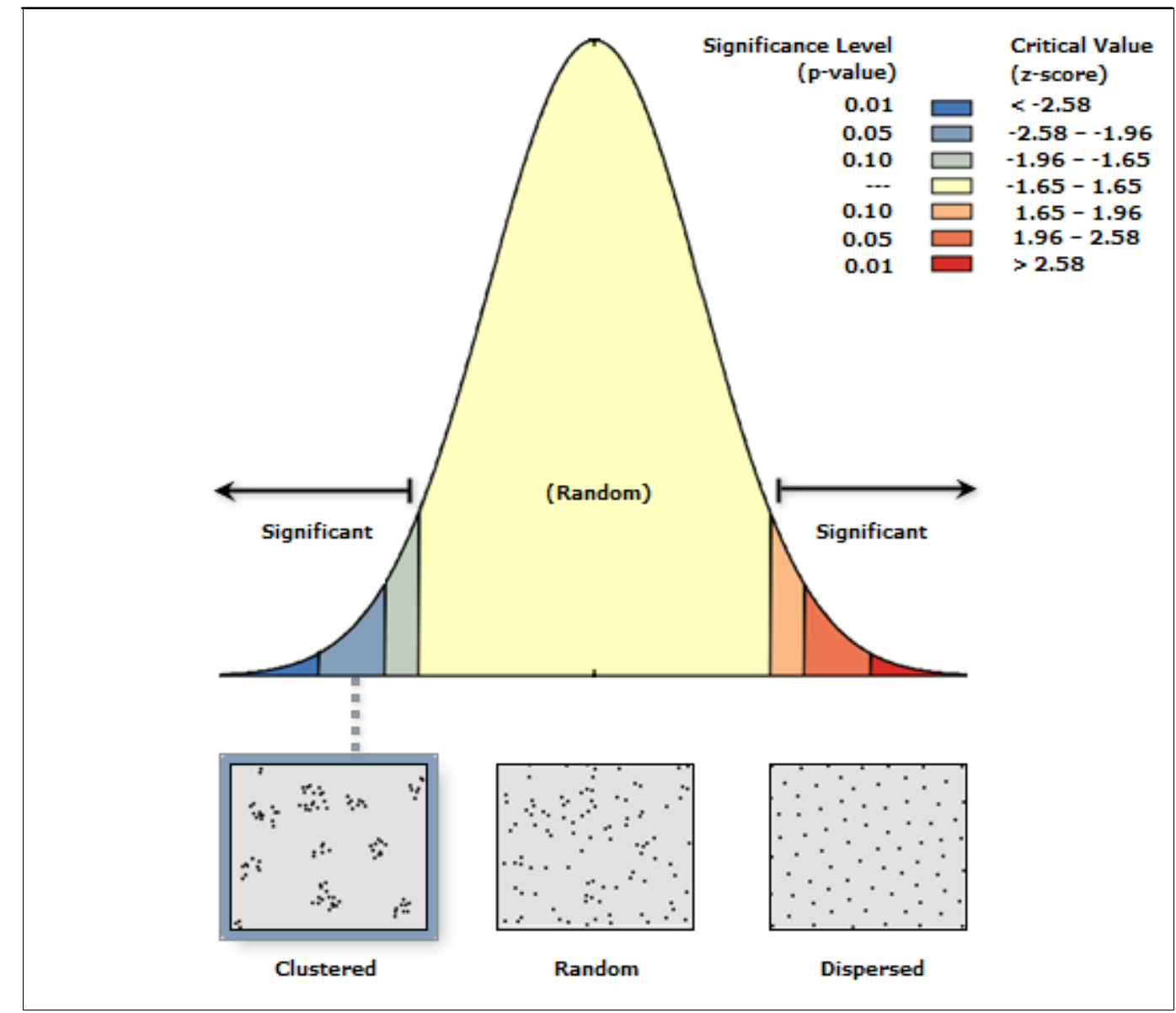

Source: Author's computation, 2018

Figure 8. Sources distribution pattern in the study area 


\section{Relationship between climatic variables and water sources and supplied}

The resulting correlation matrix from the Spearman rank correlation analysis is presented in Table 4 . The results indicated a strong negative relationship $(\mathrm{r}=-.607)$ between water supply and rainfall amount at $95 \%$ confidence level. This suggests that as rainfall increases, water supply decreases, and vice versa. The result is similar to the conclusion of Ifabiyi and Adedeji (2014) which revealed a statistically significant negative relationship between rainfall and water supply in Ilorin. They attributed such scenario to challenges in treating the water, because high rainfall amount increases the water turbidity. In addition, water supply exhibits negative relationship with minimum temperature $(\mathrm{r}=-0.341)$ and relative humidity $(\mathrm{r}=-0.368)$, which are not statistically significant at both 95 and $99 \%$ confidence levels. On the other hand, water supply exhibit mild positive relationship with highest temperature and evaporation, which are not statistically significant.

Table 4. Association between weather variables and water supply in the study area

\begin{tabular}{lccccc}
\hline Variables & Rainfall & $\begin{array}{c}\text { Minimum } \\
\text { temperature }\end{array}$ & $\begin{array}{c}\text { Maximum } \\
\text { temperature }\end{array}$ & Evaporation & $\begin{array}{c}\text { Relative } \\
\text { humidity }\end{array}$ \\
\hline Water Supply & $-0.607^{*}$ & -0.341 & 0.278 & 0.379 & -0.368 \\
Rainfall & & 0.268 & $-0.831^{* *}$ & $-0.918^{* *}$ & $0.911^{* *}$ \\
Minimum Temperature & & & 0.154 & -0.117 & 0.316 \\
Maximum Temperature & & & & $0.923^{* *}$ & $-0.852^{* *}$ \\
Evaporation & & & & $-0.956^{* *}$ \\
\hline
\end{tabular}

Source: Author's Computation, 2018

Note:

*. Correlation is significant at the 0.05 level (2-tailed).

**. Correlation is significant at the 0.01 level (2-tailed).

Rainfall amount exhibits a strong positive relationship with relative humidity $(\mathrm{r}=0.911)$, but strong negative relationship with maximum temperature $(\mathrm{r}=-0.831)$ and evaporation $(\mathrm{r}=-0.918)$ which is statistically significant at 0.01 level of confidence. Maximum temperature exhibit strong positive relationship with evaporation $(r=0.923)$ but strong negative with relative humidity $(r=$ $-0.852)$ at 0.01 level of confidence. This suggested that as maximum temperature increases evaporation also increases and vice versa. However, increase in maximum temperature brings reduction in relative humidity. Evaporation and relative humidity exhibit strong negative relationship $(\mathrm{r}=-0.956)$ at the 0.01 confidence level.

The data was further subjected to multiple regression analysis, this enables us to determine the percentage of water supply variability that can be attributed to the climate variables used in this study. The dependent variable is water supply, while the independent variables are rainfall, minimum and maximum temperature, evaporation and relative humidity. The results obtained are displayed in Table 5. This multiple linear regression model, with five explanatory variables, has an $\mathrm{R}$ squared value of 0.643 . This implied that the selected climatic variables explained $64.30 \%$ of water supply variability, while the remaining $36 \%$ of the variation is attributed to factors such as management practices, water leakages and treatment challenges, etc. 
Table 5. Relationship between climate variables and water supply

\begin{tabular}{lccccc}
\hline $\begin{array}{l}\text { Independent variables } \\
\text { and intercept }\end{array}$ & $\begin{array}{c}\text { Regression } \\
\text { coefficient }\end{array}$ & $\begin{array}{c}\text { Standard } \\
\text { error }\end{array}$ & T-test & $\begin{array}{c}\text { Significance } \\
\text { level }\end{array}$ & $\begin{array}{c}\mathbf{R}^{2} \\
\text { \% explanation }\end{array}$ \\
\hline Intercepts & 1.413 & .630 & 2.243 & - & $64.30 \%$ \\
Rainfall amount & -.001 & .001 & -2.309 & 0.060 & \\
Minimum Temperature & -.011 & .023 & -.469 & 0.655 & \\
Maximum Temperature & -.002 & .022 & -.112 & 0.914 & \\
Evaporation & .002 & .026 & .094 & 0.928 & \\
Relative humidity & .006 & .006 & .937 & 0.385 & \\
\hline
\end{tabular}

Source: Author's computation, 2018

The result of the multiple regression suggests that for every $1 \%$ decline in rainfall, in minimum and maximum temperature, there is $0.001 \%, 0.011 \%$ and $0.002 \%$ decrease in water supply, respectively. Also, for every $1 \%$ increase in evaporation and relative humidity, there is $0.002 \%$ and $0.006 \%$ increase in water supply, respectively. Based on the results obtained, the relationship between water supply and climatic variables in the study area can be represented in equation 1:

WaterSupply $=1.413-.001_{\text {Rainf allAmount }}-.011_{\text {MinimumTemperature }}-.002_{\text {MaximumTemperature }}+002_{\text {Evaporation }}+.006_{\text {RelativeHumidity }} \ldots$

\section{Relationship between climatic variables and groundwater level}

Groundwater level exhibits a strong positive relationship ( $r=0.829)$ with rainfall amount at $99 \%$ confidence level (Table 6). This suggests that as monthly rainfall increases, monthly groundwater level increases, and vice versa. This result is similar with the findings of Ashaolu (2015) which revealed a statistically significant positive relationship between monthly rainfall and groundwater. Groundwater level also exhibits a strong positive relationship $(r=.716)$ with relative humidity at $99 \%$ confidence level, which means that as monthly relative humidity increases, monthly groundwater level increases, and vice versa. Meanwhile, groundwater level exhibit negative relationship with maximum temperature $\left(\mathrm{r}=-0.704^{*}\right)$ and evaporation $(\mathrm{r}=$ $\left.0.716^{* *}\right)$, which are statistically significant at both $95 \%$ and $99 \%$ confidence levels. These results indicated an inverse relationship between groundwater level and maximum temperature as well as evaporation. Meanwhile, groundwater exhibits a positive relationship with minimum temperature which is not statistically significant.

Table 6. Association between weather variables and groundwater level in the study area

\begin{tabular}{lccccc} 
Variables & Rainfall & $\begin{array}{c}\text { Minimum } \\
\text { temperature }\end{array}$ & $\begin{array}{c}\text { Maximum } \\
\text { temperature }\end{array}$ & Evaporation & Relative humidity \\
\hline Groundwater level & $0.829^{* *}$ & 0.054 & $-0.704^{*}$ & $-0.713^{* *}$ & $0.716^{* *}$ \\
Rainfall & & 0.268 & $-.831^{* *}$ & $-.918^{* *}$ & $.911^{* *}$ \\
Minimum temperature & & & 0.154 & -0.117 & 0.316 \\
Maximum temperature & & & & $.923^{* *}$ & $-.852^{* *}$ \\
Evaporation & & & & $-.956^{* *}$ \\
\hline
\end{tabular}

Source: Author's computation, 2018

Note:

*. Correlation is significant at the 0.05 level (2-tailed).

**. Correlation is significant at the 0.01 level (2-tailed). 
The data was later subjected to multiple regression analysis which enables us to determine the percentage of groundwater level variability that can be attributed to the climate variables in the study area. The dependent variable is groundwater level, while the independent variables are rainfall, minimum and maximum temperature, evaporation and relative humidity. The results obtained are displayed in Table 7. The multiple linear regression model, with five explanatory variables, has an $\mathrm{R}$ squared value of 0.801 . This implied that $80.10 \%$ of the variation in groundwater level can be explained by this model. In other words, rainfall amount, minimum and maximum temperature, evaporation and relative humidity combined to explain $80.10 \%$ of the monthly variability of groundwater level in the study area. This indicates that other factors contributed about $20 \%$ to the variation in groundwater level besides the climatic variables in the study area. Such factors could be the aquifer type and depth of the well among others.

Table 7. Relationship between climate variables and groundwater level

\begin{tabular}{|c|c|c|c|c|c|}
\hline $\begin{array}{ll}\text { Independent } & \text { Variables } \\
\text { and intercept } & \end{array}$ & $\begin{array}{l}\text { Regression } \\
\text { coefficient }\end{array}$ & $\begin{array}{c}\text { Standard } \\
\text { error }\end{array}$ & T-test & $\begin{array}{c}\text { Significance } \\
\text { level }\end{array}$ & $\begin{array}{c}\mathbf{R}^{2} \\
\text { \% explanation }\end{array}$ \\
\hline Intercepts & 149.406 & 190.851 & .783 & - & \\
\hline Rainfall amount & .412 & .150 & 2.743 & .034 & \\
\hline Minimum temperature & -10.135 & 6.967 & -1.455 & .196 & $80.10 \%$ \\
\hline Maximum temperature & -3.025 & 6.523 & .464 & .659 & \\
\hline Evaporation & -10.536 & 7.746 & 1.360 & .223 & \\
\hline Relative humidity & 2.203 & 1.849 & 1.191 & .279 & \\
\hline
\end{tabular}

Source: Author's computation, 2018

The result of the multiple regression indicated that for every $1 \%$ increase in monthly rainfall, and relative humidity, there is $0.412 \%$ and $2.203 \%$ increase in groundwater level, respectively. Also, for every $1 \%$ decrease in minimum and maximum temperature; and evaporation, there is $10.135 \%, 3.025$ and $10.536 \%$ decrease in groundwater level, respectively. From the results obtained, the relationship between groundwater level and climatic variables in the study area can be represented as shown in equation 2 :

GroundwaterLevel $=149.406+.412_{\text {Rainf allAmount }}-10.135_{\text {MinimumTenperature }}-3.025_{\text {MaximumTemperature }}-10.536_{\text {Evaporation }}+2.203_{\text {Relativehumidity }} \ldots$

\section{Conclusion and recommendations}

Rainfall amount, minimum and maximum temperature, and evaporation exhibit an upward trend in the study area which are not statistically significant. The fluctuating trend in these climatic variables, though not statistically significant are probably related to the already established changes in climatic parameters in Nigeria. The spatial distribution of public boreholes in the study area are heterogeneous, which may not be unconnected to the cost of drilling borehole and the ability of the political leaders in each of the wards to attract such borehole projects to their various wards. The observed cluster pattern of water sources, especially the shallow wells can be attributed to the fact that the study area is located on a Basement Complex aquifer, which is a shallow aquifer that encourages proliferation of hand dug wells because of the low cost of digging. It is therefore concluded that the clustered pattern in water sources, especially hand dug wells may lead to over abstraction of groundwater in the study area. 
From the point of view of time spent and distance trekked to water sources, accessibility to water in the study area is fairly good. Finally, water management challenges are evidence with the lack of metrological station in the study area to give on site records of climatic situations. In addition, the high contribution of the climatic parameters to variability in groundwater level in the study area is therefore attributed to the shallowness of groundwater in the study area which allow it to respond more to the vagaries of climate variability. In view of the above, the following recommendations are made.

The stakeholders in charge of the water supply in the study area should seek for the establishment of a functioning meteorological station in the study area. The station can cater for the collection of climatic data that will further enhance the understanding of the impact of climate on water resources in Offa, Kwara State, Nigeria. The clustering of water sources, especially the shallow wells should be discouraged to avoid over abstraction of groundwater in the study area.

\section{References}

Abaje, I.B. (2010). Recent trends in the rainfall supply and its implication for infrastructural development. 51 $1^{\text {st }}$ Annual Conference of the Association of Nigeria Geographers. Kogi State University Ayingba, Nigeria. 7-11 March.

Abdulsalam, M.D. (2009). The development of the railway system and its impact in Offa, Kwara State: 1912-1955. Global Journal of Human Social Science: E-Economics, 14(5), 16-23.

Adedayo, A.F., \& Ifabiyi, I.P. (1999). The distribution of water and the role of public agencies in Kwara State. Journal of Social and Management Studies, 97-111.

Anyadike, R.N.C. (1993). Seasonal and annual rainfall variations over Nigeria. International Journal of Climatology, 3, 567-580.

Alley, W.M., Reilly, T.E., \& Franke, O.L. (1999). Sustainability of ground-water resources. U.S.: Geological Survey Circular.

APEC Water. (2017). The importance of water and your health. Retrived from http://www.freedrinkingwater

Chessbrough, M. (2000). District laboratory practice for tropical countries part 2. Cambridge, Cambridge University Press.

Climate Change - Glossary (2012). Education Center - Arctic Climatology and Meteorology. NSIDC National Snow and Ice Data Center. Glossary, in IPCC TAR WG1

Comprehensive Assessment of Water Management in Agriculture (CA). (2007). Water for food, water for life: A comprehensive assessment of water management in agriculture. Retrieved from http://www.iwmi.cgiar.org

Environmental Resource Management (ERM). (2009). Managing your water sustainability: An ERM guide for business. ERM Group.

Ifabiyi, I.P., \& Adedeji, A.O. (2014). Analysis of water property for Irepodun Local Government Area of Kwara State. Nigeria Journal of Russian Geographical Society, 4(4), 81-94.

Green, T.R., Taniguchi, M., \& Kooi, H., (2007). Potential impacts of climate change and human activity on subsurface water resources. Vadose Zone Journal, 6(3), 531-532.

IPCC. (2001). Climate change: Impacts, adaptations and vulnerabilities. Third Assessment Report of IPCC, Cambridge University Press. New York, 75-108. 
John, O. (2009). Nigeria and climate change: Road to cop 15, achieving the best outcome for Nigeria. Nigeria, Federal Ministry of Environment.

Makanjuala, O., Salami, W., Ayanshola, M., Aremu, A., \& Yusuf, O. (2010). Impact of climate change on surface water resources of Ilorin. $2^{\text {nd }}$ Annual Civil Engineering Conference. University of Ilorin, Nigeria. 26-28 July.

Mulcheiber, P., \& Sparks, D. (2005). Climate variability, climate change and water resources strategies from municipalities. Report to the water research commission, University of Cape Town.

Nnaji, A.O. (2001). Forecasting seasonal rainfall for agricultural decision making in northern Nigeria. International Journal of Agriculture and Forest Meteorology, 107 (3), 193-205.

Naga, C., Talnan, H., Ziyanda, M., \& Issiaka, S. (2018). The impact of climate change on water resource availability in a trans-boundary basin in West Africa: The case of Sassandra. Hydrology, 5(12). http://doi.org/10.3390/hydrology5010012

Odjugo, P.A.O. (2009). Quantifying the cost of climate change impact in Nigeria: Emphasis on wind and rainstorm. Journal of Human Ecology, 28(2), 93-101.

Odjugo, P.A.O. (2005). An analysis of rainfall pattern in Nigeria. Global Journal of Environmental Sciences, 4(2), 139-145.

Olanrewaju \& Akpan. (2016). Analysis of impact of climate variability on water accessibility and apply in Yauri, Kebbi State, Nigeria. Journal of World Development Studies, 2(2), 145163.

Scott, D. (2004). Climate change and the distribution of climatic resources for tourism in North America. Climate Research, 27(2), 105-117.

Taylor, R., \& Callist, T. (2011). The impacts of climate change and rapid development on weathered crystalline rock aquifer systems in the humid tropics of sub-Saharan Africa: evidence from South-western Uganda. In Treidel, H., Martin-Bordes, J.L., \& Gurdak, J.J. (Eds.), Climate Change Effects on Groundwater Resources: A Global Synthesis of Findings and Recommendations (pp. 17-30). USA, CRC Press.

Ulor, C.O. (2006). An Assessment of Shifts in Significant Rainfall Months in Owerri. Unpublished B.Sc Project, Department of Geography and Environment, Imo State University, Owerri, Nigeria.

World Health Organization (WHO). (2005). Guidelines for drinking water quality. Geneva, Switzerland, WHO.

WHO/ United Nations Children Fund Joint Monitoring Program (UNCFJMP, 2012): Progress on Drinking Water and Sanitation, 2012 Report from World Health Organization and UN Children's Fund, New York.

Wright, B., Stanford, B., Weiss, J., Debroux, J., Routt, J., \& Khan, S. (2013). Climate change: How does weather affect surface water quality? American Water Works Association, 39(1), $10-15$. 